\title{
Effect of port angle of sen on melt flow in a mold
}

\begin{abstract}
The molten metal from tundish is directed to continuous casting mold by submerged entry nozzle (SEN). The SEN is usually bifurcated nozzle, which is made of different shape and angle. The melt flow structure in mold plays an important role. Thus, port of SEN is made at different angles to control the melt structure. Many authors have reported that longitudinal high magnitude of melt and subsequent production of turbulence causes severe defects in casted products. In the present work, the melt flow structure has been studied under different port angles. It has been seen that melt flow has been modified in the continuous casting mold. Moreover, it was found that the change in SEN port angle affects vertical downward velocity and turbulence behavior in the molten steel region.
\end{abstract}

Keywords: SEN, port angle, mold, continuous casting
Volume 4 Issue I - 2018

\author{
Maqusud Alam,' Mohida Manzoor² Md Irfanul \\ Haque Siddiqui ${ }^{3}$ \\ 'Department of Mechanical Engineering, Aligarh Muslim \\ University, India \\ ${ }^{2}$ Department of Civil Engineering, Kurukshetra University, India \\ ${ }^{3}$ Research Institute of Engineering Design Technology, \\ Kyungpook National University, South Korea
}

Correspondence: Md Irfanul Haque Siddiqui, Research Institute of Engineering Design Technology, Kyungpook National University, South Korea, Email siddiqui@knu.ac.kr

Received: September 20, 2017| Published: January 22, 2018

\section{Introduction}

Global share of production of steel by continuous casting is more than $95 \%{ }^{1}$ The vast application of steel makes it production process important aspect of study. ${ }^{2-5}$ The cleanliness of steel is a most required process of industry. ${ }^{6}$ Various methods have been used to enhance the properties of steel during solidification. The continuous casting mold and submerged entry nozzles play an important part to produce the clean and defect free solidified slabs. ${ }^{7}$ The melt flow structure in the mold has a greater impact on solidified slabs. The velocity and turbulence can be modified by SEN. ${ }^{8}$ The SEN has few ports that can alter flow structure by modifying the angle. The research effort has been made to improve the quality of steel. Many studies reported that large vertical velocity and turbulence in the mold region causes many defects in the steel product. From previous work, it has been noted that fluid flow behavior in the mold region depends on the SEN different parameters such as mold thickness, port thickness, port angle etc. ${ }^{7,9-12}$ In the present work, numerical investigation has been carried out to find out the effect of SEN port angle on the fluid flow behavior.

\section{Mathematical model}

Figure 1 shows the schematic diagram and dimensions of the computational domain. A hexahedral mesh was generated using the Ansys Design Modeler. Fluid flow in the nozzle and mold cavity was simulated by solving the governing equations using Ansys Fluent.

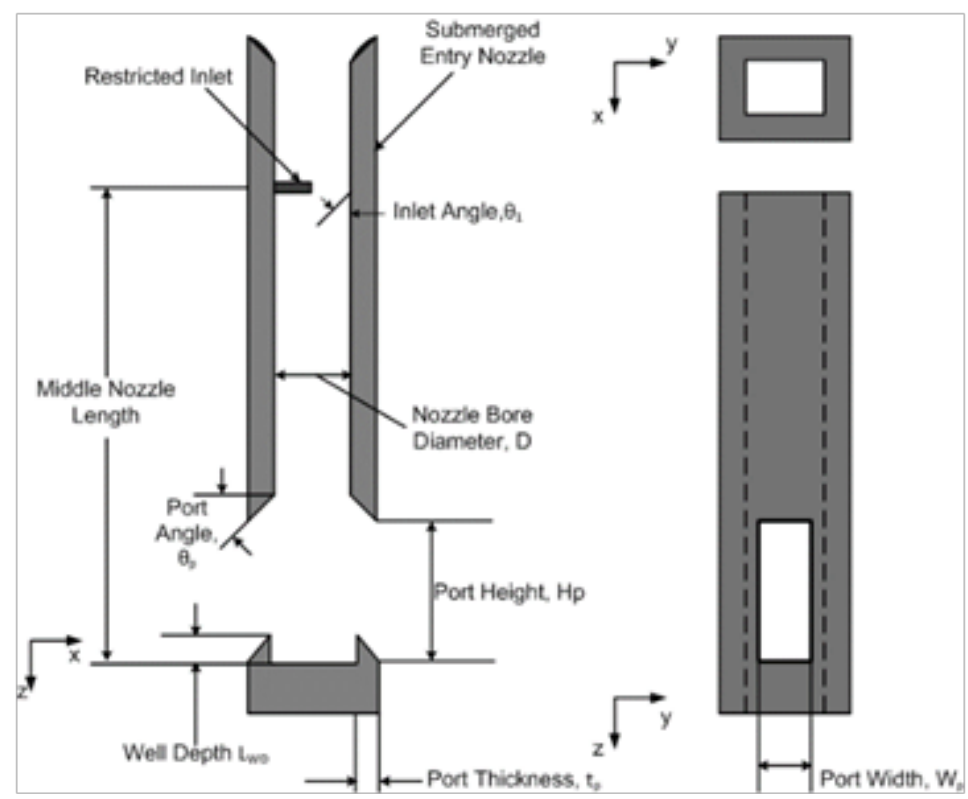

Figure I Submerged entry nozzle with port geometrical parameters. 


\section{Governing equations}

Fluid flow continuity equation.

Momentum; $\frac{\partial u_{i}}{\partial x_{j}}=0$

$$
\frac{\partial u_{i}}{\partial t}+\frac{\partial u_{i} u_{j}}{\partial x_{j}}=-\frac{1}{\rho} \frac{\partial \rho}{\partial x_{i}}+\frac{\partial}{\partial x_{j}}\left(v \frac{\partial u_{i}}{\partial u_{j}}\right)+\frac{1}{\rho} F_{i}
$$

Where, $u, \rho$ and $v$ are the velocity vector, density, and kinematic viscosity respectively.

\section{Boundary conditions}

At planes of symmetry, normal velocities, as well as all gradients, are equal to zero. Fixed velocity boundary was applied at the inlet of the nozzle and was initialized with a uniform velocity of $0.8 \mathrm{~m} / \mathrm{s}$, which was calculated based on the casting speed. The gauge pressure at the mold cavity outlets was set to zero, which is an arbitrary value that acts as a reference pressure for the rest of the domain. The boundaries defined by walls include the inner walls of the nozzle in the nozzle simulation, and the exterior walls of the nozzle, top surface, and shell boundaries in the mold cavity simulations. A no-slip condition and standard wall laws were used at these locations. Before preceding with the computation the computational model it has been validated with the experimental result. The thermos-physical properties of melt have been given in Table 1 . Table 2 shows the process parameter of the SEN nozzle port.

Table I Thermo- physical properties

\begin{tabular}{ll}
\hline Parameters & Property \\
\hline Steel density & $7020 \mathrm{Kg} / \mathrm{m}^{3}$ \\
viscosity of melt & $0.0067 \mathrm{~kg} / \mathrm{m}-\mathrm{s}$ \\
Specific heat & $750 \mathrm{j} / \mathrm{kg}-\mathrm{k}$ \\
Thermal conductivity & $41 \mathrm{w} / \mathrm{m}-\mathrm{k}$ \\
\hline
\end{tabular}

Table 2 Process parameter

\begin{tabular}{ll}
\hline $\begin{array}{l}\text { Nozzle Dimensions(along width } \times \text { along } \\
\text { Thickness) }\end{array}$ & $70 \mathrm{~mm} \times 60 \mathrm{~mm}$ \\
SEN submergence depth & $220 \mathrm{~mm}$ \\
Port height & $60 \mathrm{~mm}$ \\
Port width & $40 \mathrm{~mm}$ \\
Port angle & Varied \\
Side dispersion angle & 0 \\
Port thickness & $25 \mathrm{~mm}$ \\
Well depth & $20 \mathrm{~mm}$ \\
Nozzle inlet velocity & $0.8 \mathrm{~m} / \mathrm{s}$ \\
\hline
\end{tabular}

\section{Results and discussions}

Nozzle Flow: Figure 2(a-c) represents the instantaneous velocity contour of nozzle port outlet which shows the fluid flow direction under the conditions of $0^{0}, 15^{0}, 30^{\circ}$ port angle respectively.

Mold Flow: The differences of the flow pattern in the mold can be seen under various port angles. Figure $3(\mathrm{a}-\mathrm{c})$ shows the time-averaged velocity streamlines in Figure 3(a) for the SEN ports impinges on the narrow faces and splits into upward and downward flows forming two recirculation regions an upper vortex between jet and meniscus and a lower recirculation region in the $0^{0}$ port angle cases.

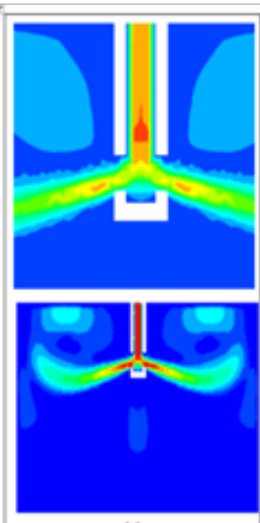

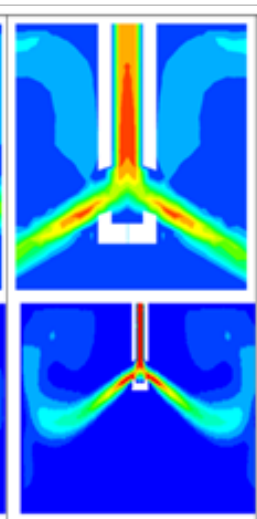

(b)

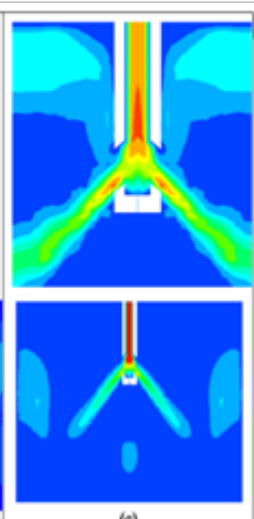

(c)
Figure 2 Contour of Instantaneous velocity (a) $0^{\circ}$ (b) $15^{\circ}$ (c) $30^{\circ}$ port angle respectively.

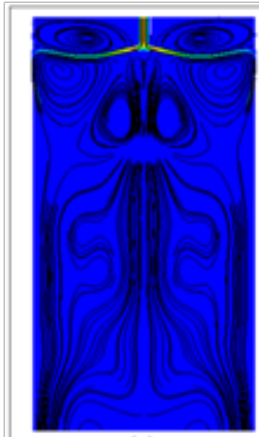

(a)

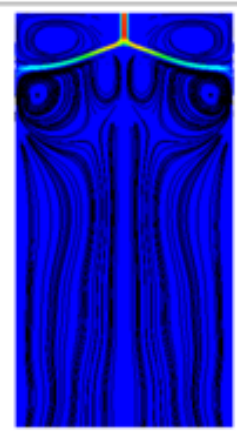

(b)

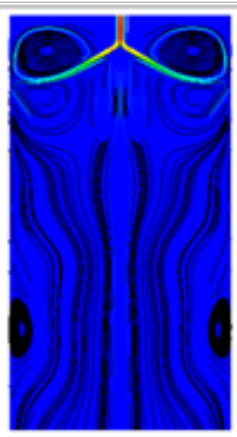

(c)
Figure 3 Contour of time average streamline velocity (a) $0^{\circ}$ (b) $15^{\circ}$ (c) $30^{\circ}$ port angle respectively.

As port angle changes from $0^{0}$ to $15^{\circ}$ also split in the upward and downward flows forming two recirculation regions but below the SEN whole region no circulation region is formed and streamline velocity appears to be smooth in Figure 3(b). With the further increase in the port angle from $15^{\circ}$ to $30^{\circ}$ near the SEN region streamline velocity contour appears to be approx same but in the mold lower portion two small circulation region appears as shown in Figure 3(c). The downward average vertical velocity for varying the port angle at different vertical portion across the mold width has been plotted in Figure 4. Figure 4(a-d) shows the graph of average downward vertical velocity across mold width at $Z=0.8 \mathrm{~m}, Z=1.2 \mathrm{~m}, Z=1.6 \mathrm{~m}$ and $\mathrm{Z}=3.0 \mathrm{~m}$, respectively and from the streamline velocity contour appearance one can conclude that $15^{0}$ port outlet angle gives the uniform downward vertical velocity. 


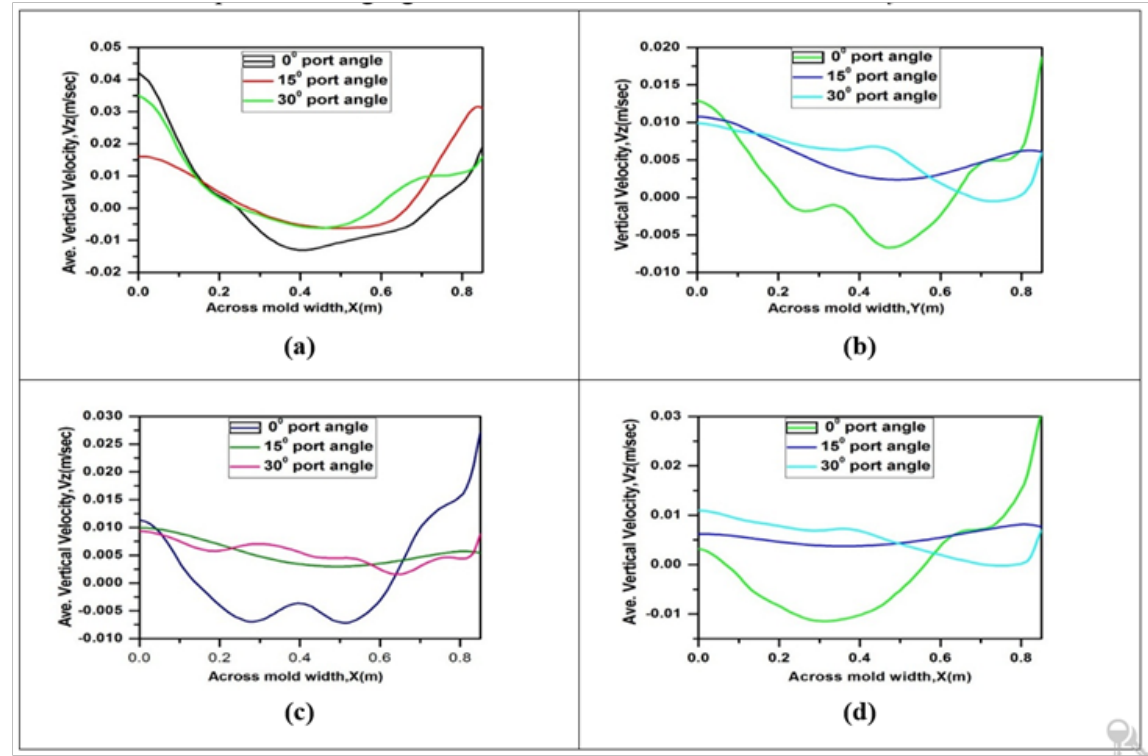

Figure 4 average vertical velocity at different port angle across mold width at (a) $Z=0.8 \mathrm{~m}$ (b) $\mathrm{Z}=1.2 \mathrm{~m}$ (c) $\mathrm{Z}=1.6 \mathrm{~m}$ (d) $\mathrm{Z}=3.0 \mathrm{~m}$.

\section{Conclusion}

Numerical modeling has been carried out to analyze the effect of SEN port angle on the fluid flow structure in the mold. Three different port angles have been designed for the investigations. It was seen that turbulence in the molten region decreases when the port angle varies from $0^{\circ}$ to $15^{\circ}$. In contrast to this situation, turbulence has been seen increased when the port angle was changed from $15^{\circ}$ to $30^{\circ}$. Moreover, a greater shift in mold structure has been noted at $30^{\circ}$ port angle. In case of $15^{\circ}$ port angle, the vertical velocity is uniform across the mold width.

\section{Acknowledgements}

None.

\section{Conflicts of interest}

Author declares that there is none of the conflicts.

\section{References}

1. World Steel Association. World Steel in Figures. 2017. p. 1-17.

2. Mazumdar D, OP Singh, J Dutta, et al. Transactions of the Indian Institute of Metals. 2011;64:593.

3. MIH Siddiqui, PK Jha. Assessment of Turbulence Models for Prediction of Intermixed Amount with Free Surface Variation Using Coupled LevelSet Volume of Fluid Method. ISIJ International. 2014;54(11):2578-2587.

4. MIH Siddiqui, PK Jha. Effect of Inflow Rate Variation on Intermixing in a Steelmaking Tundish during Ladle Change-Over. Steel Research International. 2015;87(6):733-744.

5. MIH Siddiqui, PK Jha. Steel Research International. 2015;86:799.
6. MIH Siddiqui, PK Jha. Numerical Investigation of Inclusion Behaviour in a Multi-Strand Tundish During Strand Blockages. Journal of the Institution of Engineers (India): Series D. 2015;96(2):123-130.

7. Bai H, Thomas BG. Bubble Formation during Horizontal Gas Injection into Downward Flowing Liquid. Metallurgical and Materials Transactions B: Process Metallurgy and Materials Processing Science. 2001;32(6):11431159.

8. Ruhul Amin M, Mahajan A. Numerical Investigation of the Effects of Turbulence from Submerged Entry Nozzle during Continuous Casting Process. Numerical Heat Transfer, Part A: Applications. 2004;46(3):221240 .

9. Yang Y, Jönsson PG, Ersson M, et al. Design of Magnetic Fields for Half and Full Type Electromagnetic Swirl Flow Generators. Steel Research International. 2014;86(4):361-374.

10. Ramos-Banderas A, Morales RD, Sánchez-Pérez R, et al. Dynamics of two-phase downwards flows in submerged entry nozzles and its influence on the two-phase flow in the mold. International Journal of Multiphase Flow. 2005;31(5):643-665.

11. Tsukaguchi Y, Hayashi H, Kurimoto H, et al. Development of Swirlingflow Submerged Entry Nozzles for Slab Casting. ISIJ International. 2010;50(5):721-729.

12. Savolainen J, Rousua, Fabritius T, et al. Modeling of Pressure Distribution inside the SEN in a Stopper-rod controlled System. Steel Research International. 2010;81(11):980-986. 